\title{
Implementasi Kebijakan Program Monitoring Dan Aspirasi Publik Melalui Media Massa Di Lingkungan Pemerintah Provinsi DKI Jakarta (Studi Kasus Dinas Komunikasi, Informatika dan Statistik DKI Periode Januari-Desember 2019)
}

\author{
Angga Noviar ${ }^{\mathrm{a}, 1, *}$, Achmad Lutfi ${ }^{\mathrm{b}, 2}$ \\ a,b Universitas Indonesia \\ 1 angganoviar@rocketmail.com *; ${ }^{2}$ achmad.lutfi@ui.ac.id \\ * corresponding author
}

\section{ARTICLE INFO}

Keywords

Policy Implementation;

Public Aspirations;

Program Implementation.

\begin{abstract}
The purpose of this paper is to find out the implementation of monitoring program and media news analysis within the Jakarta Capital City Government managed by Department of Communication, Information and Statistics for Jakarta through the Public Opinion and Aspirations Management Unit. Every aspiration conveyed by the public through the reader letter in the mass media will be analyzed, managed and followed up by the relevant instruments. Furthermore, these public aspirations will be utilized by local governments to determine the direction of development policies. In its implementation, $85 \%$ of public aspirations were not responded by related instruments. To find solutions to existing problems the author uses theories from Replay and Franklyn. Data collection from the management unit of public opinion and aspirations in the form of activity documents, reference books and journals on public policy implementation and mass media communication, as well as interviews with stakeholders. In this study, the data obtained were analyzed qualitatively. In the research process found several obstacles in the internal unit so that the targets and objectives have not been achieved, including: there are still implementers who do not carry out standard operational procedures and officers that un-routinely forward and reply emails of analyzed aspirations to the relevant regional. This paper concludes that the implementation of the media news monitoring and analysis program in the Jakarta Capital City Government is not yet on target because of the low level of compliance and smooth implementation.
\end{abstract}

\section{PENDAHULUAN}

Semenjak digulirkannya reformasi di Indonesia maka beberapa tugas teknis yang bertujuan melayani masyarakat sudah dilimpahkan kepada pemerintah daerah melalui otonomi daerah sebagaimana diatur dalam Undang-undang Nomor 23 tahun 2014 tentang Pemerintah Daerah. Berbagai kebutuhan-kebutuhan masyarakat yang semakin beragam dan kompleks menjadi tantangan tersendiri bagi pemerintah daerah dalam memenuhi kebutuhan warganya. Dalam mengakomondir kepentingan masyarakat termasuk dalam upaya pelaksanaan pembangunan melalui partisipasi publik, masyarakat dilibatkan melalui penyusunan Musyawarah Perencanaan Pembangunan (Musrenbang). partisipasi masyarakat tidak berhenti sampai disini melainkan berlanjut kepada partisipasi publik melalui kanal resmi milik Pemprov. DKI Jakarta dan media massa.

Media massa menjadi salah satu instrumen dalam menyusun kebijakan publik Selain itu perkembangan teknologi informasi mampu menjembatani partisipasi publik kepada pemerintah sebagai sarana perubahanan tata kelola daerah ke arah yang lebih baik. Undang-undang Pers Nomor 40 Tahun 1999 mengatur fungsi pers sebagai alat kontrol sosial untuk mencegah terjadinya 
penyalahgunaan kekuasaan (abuse of power). Peran media massa sebagai fourth state sesuai dengan konsep Jurgen Habermas dimana masyarakat mempunyai kesempatan seluas-luasnya untuk dapat berperan serta secara aktif serta ikut menciptakan public opinion yang pada gilirannya diharapkan akan mampu memberikan kontribusi bagi aktivitas politik untuk menciptakan suasana yang demokratis di publicsphere atau ruang publik (Graber 1992).

Pemerintah Provinsi DKI Jakarta melalui Dinas Komunikasi, Informatika dan Statistik (Diskominfotik) mengolah pemberitaan di media massa untuk menunjang kebutuhan informasi pimpinan dan jajarannya sehingga semua kebijakan yang dihasilkan sesuai dengan kondisi dan aspirasi para pemangku kepentingan di Pemerintah Provinsi DKI Jakarta. Seksi Pengelolaan Opini dan Aspirasi Publik (POAP) pada Diskominfotik Provinsi DKI Jakarta menyajikan informasi harian yang berasal dari media massa yang terkait pemberitan seputar kebijakan, program, kegiatan, dan isu-isu yang berkembang/ terkini. Untuk memenuhi kebutuhan dan keinginan aspirasi publik, setiap hari seksi POAP melakukan analisa konten surat pembaca di media massa yang selanjutnya diteruskan kepada perangkat daerah terkait untuk diselesaikan.

Namun dalam implementasinya terdapat kendala dalam capaian target, hal tersebut terlihat dari total jumlah aspirasi yang masuk dalam kurun waktu 1 (satu) tahun sebanyak 10341 aspirasi masyarakat dengan rincian 1535 aspirasi masyarakat yang direspon oleh instansi/ OPD (organisasi perangkat daerah) terkait, serta sebanyak 8806 aspirasi masyarakat yang tidak direspon oleh instasnsi/ OPD dengan presentase $85 \%$ berbanding $15 \%$. Atas permasalahan tersebut, penulis mengkaji bagaimana implementasi kebijakan program pengelolaan monitoring dan analisa berita media di lingkungan Pemerintah Provinsi DKI Jakarta.

\section{KERANGKA TEORI}

\section{Partisipasi Publik}

Ada begitu banyak makna dari teori partisipasi publik bila merujuk berbagai pendapat ahli, namun menurut Theodorson dan Theodorson (1970:83) memberikan suatu definisi partisipasi sosial yaitu: (1) "the participation of and individual in social groups"; (2) "sometimes restricted to participation in voluntary organization particularly those engaged in some type of community activity or project, out-side of an individual's professional or occupational work situations". Dengan kata lain partisipasi sosial adalah: (1) "partisipasi seseorang di dalam suatu kelompok social"; (2) "kadangkala terbatas pada partisipasi didalam organisasi secara sukarela khususnya dalam pelaksanaan program/ kegiatan atau proyek masyarakat, di luar profesi seseorang atau pekerjaan tertentu". Sedangkan menurut Sukanto (1983:425) kata partisipasi ditinjau dari segi etimologis merupakan pinjaman dari Bahasa Belanda "participation", yang sebenarnya berasal dari bahasa latin "participatio". Participatio sendiri terdiri dari dua suku kata yaitu pars yang berarti bagian dan capere yang berarti mengambil bagian. Istilah participation sendiri dibentuk dari kata kerja "participare" yang artinya ikut serta dalam suatu kegiatan. Adanya kegiatan atau aktivitas menjadi penanda bahwa partisipasi memiliki pengertian aktif.

Menurut Bakhit et. al (2001:73) partisipasi berarti memainkan peran aktif dalam penetapan tujuan dan prioritas-prioritas dalam perencanaan proyek atau program, serta terlibat dalam mengevaluasi setiap langkah yang diambil. Sedangkan Verhagen dalam Bakhit et. al (2001:73) mengemukakan instrument yang dapat dikembangkan dalam mewujudkan partisipasi adalah melalui pertukaran informasi, riset dan perencanaan partisipatif dan evaluasi partisipatif.

Mengacu kepada pengertian partisipasi tersebut diatas, membuka kemungkinan bagi setiap anggota masyarakat untuk menyumbang/ berkontribusi demi terbinanya dan terwujudnya masa depan yang baik. Bahkan partisipasi merupakan hak dan kewajiban seseorang warga negara untuk memberikan kontribusinya kepada pencapaian tujuan kelompok, sehingga masyarakat diberi kesempatan untuk ikut serta dalam pembangunan dengan menyumbangkan inisiatif dan kreatifitasnya. Sehingga tujuan partisipasi dengan melibatkan secara terus menerus dan aktif dalam pembuatan keputusan yang dapat mempengaruhi kepentingan umum" Menurut Antoft dan Novack (1998). 


\section{Faktor Implementasi Kebijakan}

Dalam penelitian ini teori utama yang digunakan sebagai pisau analisis pembahasan menggunakan teori Replay dan Franklin (1986) untuk melihat tingkat efektifitas dalam implementasi kebijakan program pengelolaan monitoring dan analisa berita media di lingkungan Pemerintah Provinsi DKI Jakarta. Teori tersebut sebagaimana yang telah diturunkan menjadi operasionalisasi konsep pada bagian metode penelitian. Model Replay dan Franklin (1986) dapat menjabarkan bahwa sisi efektifitas dalam pelaksanaan implementasi kebijakan, dimana efektifitas implementasi dapat dilihat berdasarkan pada tiga aspek seperti: (1) Tingkat kepatuhan para pelaksana kebijakan, (2) Kelancaran dalam pelaksanaan rutinitas, (3) Tercapainya Sasaran dan tujuan yang dikehendaki kebijakan.

Menurutnya Replay dan Franklin (1986) bahwa implementasi mencakup banyak macam kegiatan. Pertama, Badan-badan pelaksana yang ditugasi oleh undang-undang dengan tanggung jawab menjalankan program harus mendapatkan sumber-sumber yang dibutuhkan agar implementasi berjalan dengan lancar. Kedua, badan-badan pelaksana mengembangkan bahasa anggaran dasar menjadi arahan-arahan konkret, regulasi, serta rencana-rencana dan desain program. Ketiga, badan-badan pelaksana harus mengorganisasikan kegiatan-kegiatan mereka dengan menciptakan unit-unit birokrasi dan rutinitas untuk mengatasi beban kerja. "Istilah implementasi menunjuk pada sejumlah kegiatan yang mengikuti pernyataan maksud tentang tujuan-tujuan program dan hasil-hasil yang diinginkan oleh para pejabat pemerintah. Implementasi mencakup tindakan-tindakan (tanpa tindakan-tindakan) oleh berbagai aktor khususnya para birokrat yang dimasudkan agar untuk membuat sebuah program berjalan" (Franklin 1986).

Teori oleh Ripley dan Franklin mendekati atas kutipan oleh Dwiyanti Indiahono bahwa implementasi kebijakan adalah tahapan yang penting dalam kebijakan. Tahap ini menentukan apakah kebijakan yang dikerjakan oleh pemerintah sesuai untuk diterapkan dalam pengimplementasiannya serta dapat menghasilkan output dan outcome yang direncanakan.

\section{METODE PENELITIAN}

Pada penelitian ini menggunakan pendekatan post-positivism dengan menggunakan metode pengumpulan data secara kualitatif. Penelitian ini juga menggunakan teori sebagai guidance dan dengan variable yang jelas, karena menggunakan pendekatan post-positivism. Pendekatan postpositivism menggunakan metode pengumpulan data secara kualitatif yang berasal dari konsep teori Ripley dan Franklin (1986) menjadi teori utama dan dijadikan juga sebagai pisau analisis yang dioperasionalisasikan dalam menemukan permasalahan dipenelitian ini. Dengan menggunakan koridor pengumpulan data secara kualitatif seperti wawancara mendalam atas narasumber terkait, studi literature, studi terhadap dokumen primer dan sekunder, dan penelitian langsung di Bidang Informasi Publik Dinas Komunikasi, Informatika dan Statistik Provinsi DKI Jakarta. Berikut table yang menunjukkan operasionalisasi konsep penelitian ini:

Table 1 Operasional Konsep Penelitian

\begin{tabular}{|c|c|c|c|}
\hline Konsep & Variabel & Dimensi & Indikator \\
\hline \multirow{3}{*}{$\begin{array}{l}\text { Implementasi } \\
\text { Kebijakan }\end{array}$} & \multirow{3}{*}{$\begin{array}{l}\text { Efektifitas } \\
\text { implementasi } \\
\text { kebijakan } \\
\text { pengelolaan } \\
\text { monitoring dan } \\
\text { analisa aspirasi } \\
\text { surat pembaca }\end{array}$} & $\begin{array}{l}\text { Tingkat kepatuhan para } \\
\text { pelaksana kebijakan }\end{array}$ & $\begin{array}{l}\text { Kepatuhan pelaksana kebijakan } \\
\text { dalam melaksanakan kebijakan yang } \\
\text { tertuang dalam dokumen kebijakan }\end{array}$ \\
\hline & & $\begin{array}{l}\text { Kelancaran dalam } \\
\text { pelaksanaan rutinitas }\end{array}$ & $\begin{array}{l}\text { Berjalannya seluruh fungsi-fungsi } \\
\text { yang ada dalam organisasi }\end{array}$ \\
\hline & & $\begin{array}{l}\text { Tercapainya sasaran dan } \\
\text { tujuan yang dikehendaki } \\
\text { kebijakan }\end{array}$ & $\begin{array}{l}\text { Dirasakannya dampak atau manfaat } \\
\text { dari kebijakan }\end{array}$ \\
\hline
\end{tabular}




\section{HASIL TEMUAN DAN PEMBAHASAN}

\section{Program Monitoring dan Analisa Berita Media}

Aspirasi surat pembaca merupakan laporan baik lisan maupun tulisan kepada media massa atas keluhan-keluhan, kritik, ucapan serta bentuk informasi-infomasi lainnya dari masyarakat kepada pemerintah. Alasan publik menyampaikan aspirasi melalui media massa adalah karena faktor jangkauan pesan, netralitas dan kerahasiaan identitas pelapor. Melalui kanal pengaduan yang ada di media massa, aspirasi yang disampaikan akan mendapat efek terpaan yang lebih besar dan perhatian luas dari berbagai kalangan baik itu masyarakat, pemerintah serta pengawas kebijakan. Dari sisi netralitas, media massa dapat berperan dalam menjembatani kepentingan publik tanpa memiliki keberpihakan tertentu. Sedangkan dari sudut kerahasiaan identitas pelapor, media massa tidak mencantumkan identitas pelapor dalam setiap penyampaikan pengaduan aspirasi publik.

Gambar 1 Chart aspirasi masyarat

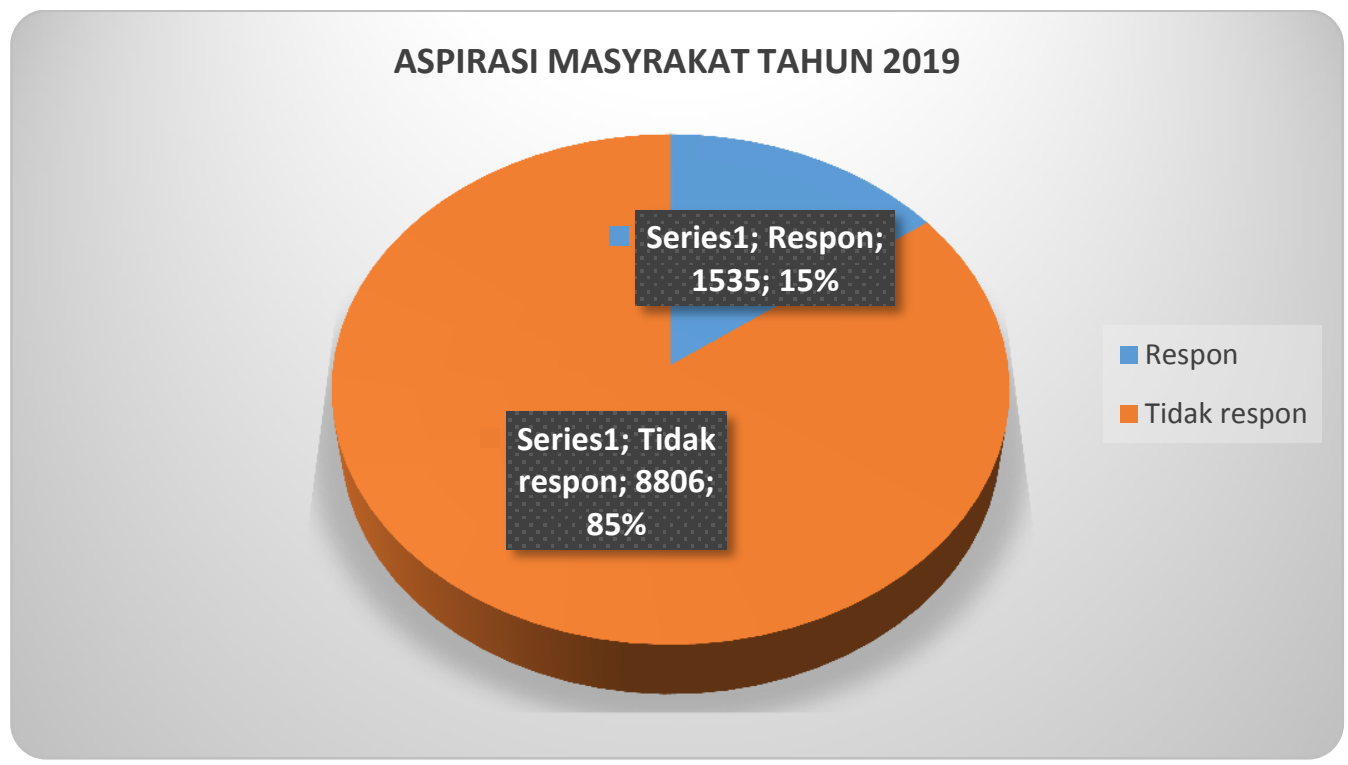

Sumber: Seksi Pengelolaan Opini dan Aspirasi Publik tahun 2019

Dalam pelaksanaan pengimplementasinya terdapat kendala dalam capaian target yang telah direncanakan, seperti aspirasi masyarakat yang tidak direspon oleh instasnsi/OPD dengan presentase $85 \%$ berbanding $15 \%$.

\section{Efektifitas Implementasi Kebijakan}

Dalam faktor ini menjelaskan mengenai 3 (tiga) indikator yaitu tingkat kepatuhan para pelaksana kebijakan, kelancaran dalam pelaksanaan rutinitas, tercapainya sasaran dan tujuan yang dikehendaki kebijakan. Dari ketiga indikator tersebut akan dianalisis apakah ditemui hambatan dan kendala terkait efektifitas implementasi program monitoring dan analisa berita media di lingkungan Provinsi DKI Jakarta.

\section{Analisis tingkat kepatuhan}

Dari indikator tingkat kepatuhan yang terpengaruh akan dianalisis apakah dalam implementasi program monitoring dan analisa berita media di lingkungan Provinsi DKI Jakarta ditemukan hambatan dari kepatuhan sehingga berimplikasi kepada efektifitas implementasi kebijakan.

Tingkat kepatuhan oleh pelaksana atau implementor adalah salah satu alat ukur dalam menentukan keberhasilan dan efektivitas dari suatu pelaksanaan kebijakan. Apabila petugas di Seksi POAP tidak patuh terhadap peraturan yang ditetapkan maka implementasi kebijakan tidak akan mencapai efektif. Menurut kepala bidang informasi publik raides bahwa kita memonitor, mem-validasi, mem-verifikasi pertanyaan-pertanyaan yang masuk pada media berdasarkan hasil monitoring untuk di tindaklanjuti oleh OPD sesuai dengan tupoksi masing-masing OPD, kemudian OPD merespon itu disampaikan ke kita, sesudah itu kita yang membuat jawaban dari OPD terkait 
untuk disampaikan kepada media yang membuat rubik aspirasi surat pembaca dimedia cetak masing-masing tersebut dengan cara : 1) Memanfaatkan media sosial melalui whatsapp group (sebagai upaya ekselerasi percepatan informasi sampai pada OPD terkait); 2) Secara birokrasi membuat surat secara tertulis (secara resmi/formil); 3) Menggunakan email.

Rentang waktu pengiriman aspirasi publik yang telah di analisa terkadang tidak cepat dikirim kepada OPD terkait sehingga kerapkali sering terlewat karena terlupakan. Analisa ini diperkuat melalui wawancara atas pimpinan redaktur Poskota; Kadang-kadang gini, yang saya tahu, kalau di Poskota setiap aspirasi warga yang masuk disortir kemudian diangkat untuk naik cetak, kemudian biasanya para Lurah dan Walikota-nya lebih cepat merespon secara langsung atas keluhankeluhan warganya tersebut. Diskominfo Provinsi DKI Jakarta bahkan belum sempat respons, itu (aspriasinya). Sering banget itu. Jadi berdasarkan aspriasi ini, kami teruskan. Hal tersebut tidak jadi masalah bagi kami.

Dari wawancara kabid informasi publik di Dinas Komunikasi, Informatika Provinsi DKI Jakarta, selaku penanggung jawab program monitoring dan analisa berita didapat bahwa, pekerjaan yang menjadi tanggung jawab implementer untuk mengirim hasil monitoring yang telah dianalisa kepada instansi terkait melalui surat resmi, email, dan whatsapp tidak berjalan efektif. Hal tersebut dapat dilihat dari hasil wawancara dari pimpinan redaksi harian cetak poskota bahwa kecepatan respon ada pada tingkat Lurah dan Walikota yang bertanggung jawab. Tingkat kepatuhan implementer dalam hal kecepatan menyampaikan aspirasi masyarakat kepada instansi terkait memerlukan pemahaman yang baik terhadap alur pekerjaan berdasarkan koridor standar operasional prosedur (SOP) di seksi pengelolaan opini dan aspirasi publik. Hasil analisa yang cepat diterima oleh OPD dapat mempengaruhi juga respon balik atas aspirasi masyarakat yang diterima. Berdasarkan SOP yang ada terlihat rentang waktu analisa.

\section{Kelancaran dalam pelaksanaan rutinitas}

Dengan kelancaran pelaksanaan implementasi kebijakan dapat menentukan arah yang benar sehingga pelaksanaan dapat berjalan sesuai koridor sehingga hasil yang capai sesuai dengan perencanaan. Kelancaran dapat juga diartikan sebagai hal yang tidak tersendat-sendat, aktivitas yang lancar maka mendapatkan pengertian yang positif, karena dengan kelancaran maka bermuara pada tujuan yang hendak dicapai. Dilihat dalam pelaksanaan rutinitas yang berlaku di Seksi Pengelolaan Opini dan Aspirasi Publik bahwa keberhasilan atas program aspirasi masyarakat yang disajikan oleh media massa ditandai dengan adanya kelancaran dan pelaksanaan rutinitas. Dengan jumlah aspirasi masuk melalui media massa yang dikelola oleh Seksi POAP memerlukan konsistensi implementer sehingga kelancaran arus informasi dapat dijaga kelancarannya.

Pekerjaan yang dilakukan secara rutinitas adalah untuk dapat mengindentifikasi dan merangkum aspirasi masyarakat yang disampaikan melalui media massa cetak, online dan televisi serta berkoordinasi dengan organisasi perangkat daerah terkait tindaklanjut klarifikasi berita tersebut dan sesuai dengan kerangka acuan kerja didalan Seksi POAP. Untuk pekerjaan yang diberikan tanggung jawab khusus untuk mengerjakan aspirasi yang masuk melalui media massa terdiri dari 1 (satu) kordinator dari aparatur sipil negara (ASN) serta dibantu oleh 2 (dua) orang tenaga terampil sebagai operator yang ditugaskan berkoordinasi dengan organisasi perangkat daerah (OPD). Aspirasi masyarakat yang disajikan oleh media massa setiap harinya dikelola oleh petugas secara rutin. "Semua aspirasi kita grab tanpa ada pilih-pilih, baik itu masukan, idea, aspirasi dan lain-lain kesemua kita ambil. Karena disini kita adalah jembatan sehingga kita tidak memilah-milah. Investigasi itu adalah tugas organisasi perangkat daerah (OPD), karena biasanya permasalahan lebih banyak dari wilayah sehingga kewilayahan kita kirim juga dan kita distribusinkan hingga habis (wawancara dengan narsum, 3 Desember 2019). Petugas pelaksana yang mempunyai tanggung jawab dalam mengerjakan program aspirasi publik seperti menganalisa aspirasi masyarakat melalui media massa, mengirimkan informasi kepada OPD terkait, serta menyusun klarifikasi melalui email dan media sosial mempunyai peran yang penting dalam kelancaran pekerjaan sesuai dengan target yang dicapai. Dan apabila salah satu tugas tersebut tidak berjalan secara rutin/ terhambat maka program aspirasi publik tidak berjalan efektif. Hasil observasi di seksi pengelolaan opini dan aspirasi publik ditemukan tidak sinkronnya antara jumlah 
aspirasi yang terpublish di http://oneid.jakarta.go.id (data dalam desktop website) dengan raw materi (file dokumen asli) seperti pada gambar di bawah ini :

Gambar 2 Data Aspirasi ter-publish
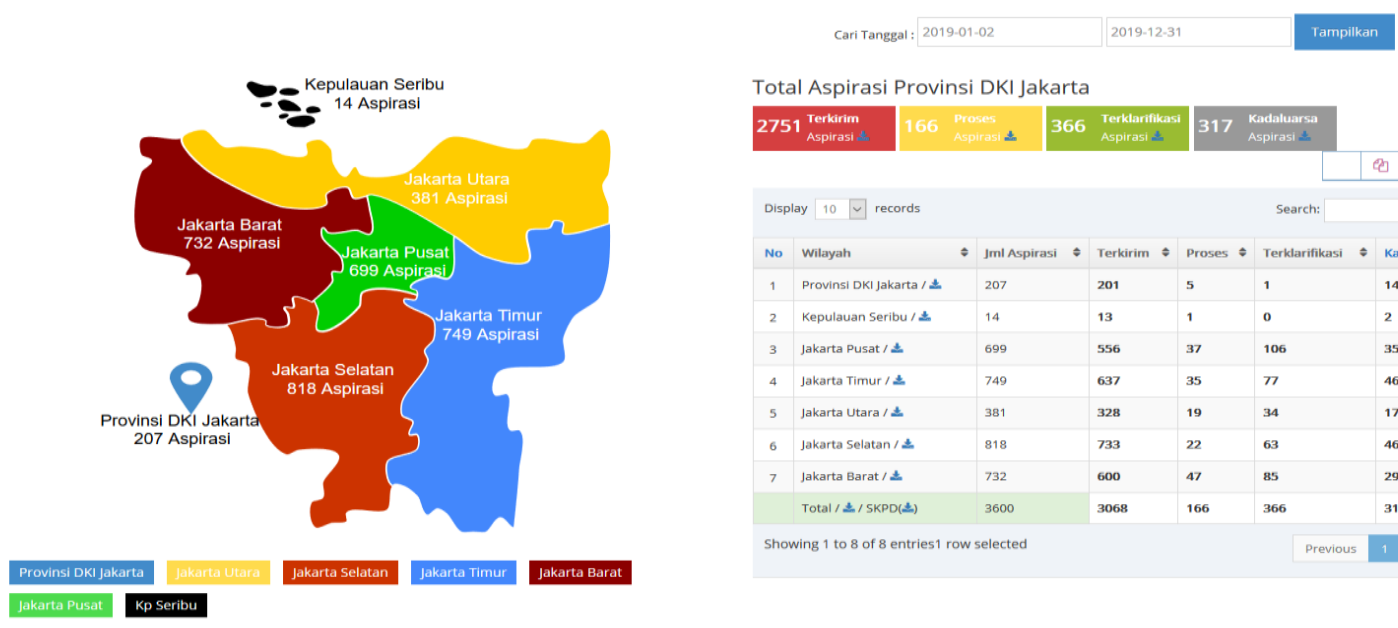

Jakarta Pusat Kp Seribu

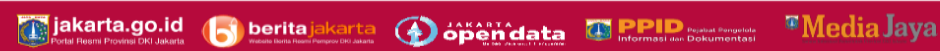

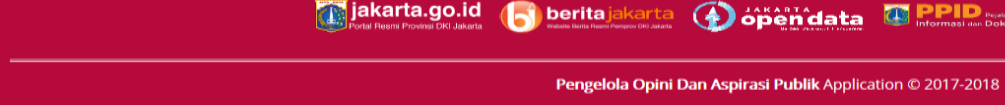

Sumber: http://oneid.jakarta.go.id

Dalam gambar terlihat jumlah aspirasi masyarakat selama tahun 2019 seperti wilayah Jakarta Selatan (818 aspirasi), disusul Jakarta Barat (732 aspirasi), Jakarta Timur (749 aspirasi), Jakarta Pusat (699 aspirasi), Jakarta Utara (381 aspirasi), Provinsi DKI (207 aspirasi), dan wilayah Kepulauan Seribu (14 aspirasi), namun dari dokumen primer yang ditemukan diarsip Seksi POAP seperti tabel dibawah ini:

Tabel 2. Data aspirasi publik raw materi

\begin{tabular}{|r|l|r|r|}
\hline \multirow{2}{*}{ No } & \multicolumn{1}{|c|}{ Wilayah } & Aspirasi Publik \\
\cline { 2 - 4 } & \multicolumn{1}{|c|}{ web jakarta.go.id (2019) } & $\begin{array}{r}\text { Dokumen Asli Seksi POAP } \\
(2019)\end{array}$ \\
\hline 1 & Jakarta barat & 732 & 5124 \\
\hline 2 & Jakarta Selatan & 818 & 5726 \\
\hline 3 & Jakarta Timur & 749 & 5243 \\
\hline 4 & Jakarta Utara & 381 & 2667 \\
\hline 5 & Jakarta Pusat & 700 & 4900 \\
\hline 6 & Kabupaten Kepulauan Seribu & 14 & 98 \\
\hline 7 & tingkat Provinsi sebanyak & 207 & 1449 \\
\hline & TOTAL & 3601 & 25207 \\
\hline
\end{tabular}

Sumber: Diolah penulis dari dokumen Seksi POAP

Berdasarkan data-data tersebut ditemukan perbedaan jumlah aspirasi yang ada baik dari file dokumen asli maupun data yang di publish melalui website. Dalam pelaksanaan dari pada program Seksi Pengelolaan Opini dan Apirasi Publik tingkat kepatuhan pada setiap petugas yang bertanggung jawab dalam melaksanakan tugas dan fungsinya untuk mengidentifikasi dan merangkum aspirasi masyarakat yang disampaikan. Tingkat kepatuhan oleh pelaksana atau 
implementor adalah salah satu alat ukur dalam menentukan keberhasilan dan efektivitas dari suatu pelaksanaan kebijakan. Ketidaksesuaian data yang terpublish dengan sumber data melalui dokumen asli Seksi Pengelolaan Opini dan Aspirasi Publik merupakan hasil akumulasi implementer dalam melaksanakan rutinitasnya.

\section{Tercapainya Sasaran dan Tujuan yang Dikehendaki Kebijakan}

Dalam pelaksanaan kebijakan program monitoring dan analisa berita media di lingkungan pemerintah Provinsi DKI Jakarta untuk mencapai keberhasilannya perlu diketahui faktor-faktor yang menggambarkan proses pengambilan keputusan melalui proses politik dan administrasi, dengan proses umum tindakan administrative yang dapat diteliti pada tingkat program tertentu oleh Grindle (1980).

Bahwa keberhasilan suatu implementasi mengacu dan mengarah pada implementasi/ pelaksanaan dan dampak (manfaat) yang dikehendaki dari pelaksanaan kebijakan. Peraturan Pemerintah Nomor 45 Tahun 2017 tentang Partisipasi Masyarakat Dalam Penyelenggaraan Pemerintahan Daerah dilandasi oleh Pasal 5 ayat (2) Undang-Undang Dasar Negara Republik Indonesia Tahun 1945. Lahirnya PP No. 45 Tahun 2017 pada hakekatnya untuk menciptakan kesejahteraan masyarakat dalam penyelenggaraan disetiap pemerintah daerah sehingga keberhasilan pembangunan dapat mengakomodir kepentingan masyarakat.

Keseriusan beberapa OPD terkait permasalahan-permasalahan yang ada dimasyarakat diperkuat hasil wawancara oleh Kepala Dinas Perhubungan Provinsi DKI Jakarta "kami sangat serius untuk menanggapi atas keluhan-keluhan yang ada dimasyarakat dan berpihak kepada kepentingan masyarakat, setiap aduan yang akan mendatangkan kemaslahatan untuk masyarakat banyak dan sesuai tugas pokok dan fungsi Dinas Perhubungan seluruhnya akan kami tangani dengan baik dan secepat-cepatnya". Untuk tercapainya sasaran serta kepentingan masyarakat OPD secara khusus memperhatikan aspirasi masyarakat, namun bagiamana dengan aspirasi yang secara akumulasi jumlahnya besar dan tidak ditindaklanjuti seperti tanggapan Kabid Informasi Publik 1 Desember 2019 "masyarakat menyampaikan hal itu agar publik tahu bahwa ini ada persoalan yang di hadapi oleh masyarakat, namun dalam kontek informasi harusnya ada respon cepat walaupun bentuknya hanya sekedar informasi normatif, karena pekerjaan perlu proses". Keseriusan implementer atas sasaran dan tujuan dari kebijakan tersebut masih memerlukan komitmen antar implementer yang terkait sehingga kebutuhan masyarakat dapat terakomodir dengan baik.

\section{PENUTUP}

\section{Simpulan}

Penelitian dengan judul "Implementasi Kebijakan Program Monitoring dan Aspirasi Publik Melalui Media Massa di Lingkungan Pemerintah Provinsi DKI Jakarta" berkesimpulan pada 3 (tiga) dimensi, seperti tingkat kepatuhan pada pelaksana kebijakan, kelancaran dalam pelaksanaan rutinitas dan tercapainya sasaran dan tujuan yang dikehendaki kebijakan. Sedangkan dari ketiga dimensi tersebut mempunyai fungsi keterikatan dalam pelaksanaan program sehingga dapat mencapai sasaran yang dikehendaki. Indikator penghambat utama adalah dari tingkat kepatuhan serta pelaksana rutinitas implementer dalam melaksanakan tugas sesuai dengan petunjuk pelaksana dan petunjuk teknis program monitoring dan aspirasi berita media. Pengawasan pelaksanaan program mempunyai peran penting dalam menjaga koridor pekerjaan sesuai dengan ketentuan yang sudah ditentukan, sehingga kepatuhan stakeholder secara responsive dapat menjawab aspirasi masyarakat.

\section{Rekomendasi}

Berdasarkan hasil analisis dilakukan, penulis berusaha untuk mencoba merekomendasikan saran sebagai berikut, bahwa faktor penghambat dalam kebijakan terutama pada faktor kepatuhan dan rutinitas. 
1. Ciptakan situasi dan kondisi urgenitas secara rutin atas jawaban aspirasi publik dari instansiinstansi terkait dengan disampaikan pemahaman, bahwa jawaban atas aspirasi publik merupakan komunikasi yang wajib disampaikan kepada masyarakat.

2. Implementasikan secara berkala dengan tingkat kepatuhan untuk memonitor pekerjaan dengan pengawasan terhadap implementor teknis yang mempunyai peran dan tugas menyampaikan hasil aspirasi publik kepada instansi yang bertanggung jawab.

3. Intensifkan secara rutin pelaksanaan sharing knowledge berupa sosialisasi serta edukasi serta mendiskusikan manfaat yang diperoleh oleh instansi di- lingkungan Provinsi DKI Jakarta dan masyarakat terkait responsifitas jawaban aspirasi masyarakat yang dapat dikelola dengan baik.

\section{DAFTAR PUSTAKA}

\section{Sumber Buku dan Jurnal}

[1]. Abdul R Nur, 2017. Implementasi Peraturan Daerah Nomor 3 Tahun 2006 Tentang Penertiban, Pengaturan Tempat Usaha dan Pembinaan Pedagang Kaki Lima di Kabupaten Bojonegoro. Universitas Negeri Semarang

[2]. Achmad Fawaid. Edisi Keempat. Cet-2. Yogyakarta: Pustaka Pelajar.

[3]. Agustino, Leo. 2006. Dasar-Dasar Kebijakan Publik. Bandung: Alfabeta.

[4]. Anderson, E. James. (1997). Public Policy-Making. Third Edition. New York: Holt, Rinchart and Winston. Badan Pusat Statistik (2014). Statistik Indonesia 2014

[5]. Caiden, Gerald E. (1969). Administrative Reform. London: Allen Lane The Penguin Press.

[6]. Caiden, Gerald E. (1991). Administrative Reform Comes Of Age. Berlin: Walter de Gruyter.

[7]. Creswell, John W. (2010). Research Design: Pendekatan Kualitatif, Kuantitatif, dan Mixed (terjemahan), edisi ketiga. Yogyakarta: Pustaka Pelajar.

[8]. Islamy, M. Irfan. (2001). Prinsip-prinsip Perumusan Kebijaksanaan Negara. Bandung: PT. Bina Aksara

[9]. Lester, James P dan Steward, Josep Jr.2000. Public Policy: An Evolutionari Approach. Belmont: Wadsworth.

[10].Mazmanian, Daniel A Et.al. (1983). Implementation and Public Policy. USA: Scott Foresman and Company.

[11].Moleong, Lexy J. (2006). Metode Penelitian Kualitatif "Edisi Revisi”. Bandung: PT. Remaja Rosda Karya.

[12].Putra, Fadilah.2003. Paradigma Kritis Dalam Studi Kebijakan Publik: Perubahan dan Inovasi Kebijakan Publik Dalam Ruang Partisipasi Masyarakat Dalam Proses Kebijakan Publik. Yogyakarta: Pustaka Pelajar.

[13].Ripley, Randall B. Dan Franklin, Grace A. (1986). Policy Implementation and Bureaucracy. Chicago: The Dorsey Press

[14].Suharto, Edi. (2008). Kebijakan Sosial Sebagai Kebijakan Publik. Bandung: Alfabeta (edisi kedua).

[15].Wahab, Solichin Abdul. 2008. Analisis Kebijaksanaan; Dari Formulasi ke Implementasi Kebijaksanaan Negara. Jakarta: Sinar Grafika.

[16].Winarno, Budi. 2008. Kebijakan Publik: Teori \& Proses. Yogyakarta: Media Pressindo.

\section{Dokumen dan Website}

[1]. Badan Statistik Nasional, 2017. Jakarta dalam Angka 2017

[2]. http://oneid.jakarta.go.id

[3]. http://analisaberita.jakarta.go.id/reportaspirasi/Aspirasi 01 Januari 2019 s/d 31 Desember 2019 diakses pada 18 Januari 2020

[4]. Laporan Tahunan Seksi Pengelolaan Opini dan Aspirasi Publik tahun 2018

[5]. Ombudsman RI, Informasi Statistik Penyelesaian Laporan Tim Penjaminan Mutu 2016 